\title{
The influence of obesity on the worsening of inflammatory processes and Diabetes Mellitus
}

\author{
Elane Barbosa de Aguiar'; ;osé Carlos Domingues de França Filho²; Maria Vitória Lins da Silva ${ }^{3}$; \\ Daniela Phênix Oliveira Guimarães ${ }^{4}$; Wictória Brinalda Gomes Ferreira ${ }^{5}$; Paulo Cesar da Silva ${ }^{6}$; \\ Maria Karolayny Barbosa Andrade Silva ${ }^{7}$; Rosângela de Almeida Landim ${ }^{8}$; Liandra Larissa \\ Ferreira da Silva'; Jerfesson Correia da Silva ${ }^{10}$; Bruna Michele da Silva Almeida ${ }^{11}$; Maria Geralda \\ de Sousa Silva ${ }^{12}$; Izabele Moreira dos Santos ${ }^{13}$; Hellen Beatriz Gomes da Silva ${ }^{14}$; Allyson Rodrigo de \\ Oliveira Lopes*15
}

1 - 14 Undergraduate Nursing students at Academic Center of Vitória de Santo Antão - UNIVISA.

15 Professor of the Bachelor's degree in the Nursing course at Academic Center of Vitória de Santo Antão - UNIVISA.

E-mail adresses: allysonlopes85@gmail.com (Allyson Rodrigo de Oliveira Lopes)

${ }^{*}$ Corresponding author

\section{To cite this article:}

Aguiar, E, B.; Filho, J.C.D.F.; Silva, M.V.L.; Guimarães, D.P.O.; Ferreira, W.B.G.; Silva, P.C.; Silva, M.K.B.A.; Landim, R.A.; Silva, L.L.F.; Silva, J.C.; Almeida, B.M.S.; Silva, M.G.S.; Santos, I.M.; Silva, H.B.G.; Lopes, A.R.O. The influence of obesity on the worsening of inflammatory processes and Diabetes Mellitus. International Journal of Sciences. Vol. 2, No. 1, 2021, pp. 31-33. ISSN $2763-5392$.

Received: 06 29, 2021; Accepted: 06 30, 2021; Published: 07 15, 2021

\begin{abstract}
Although today it is considered a chronic disease, for a long-time humanity has cultivated it as synonymous with opulence and charm. However, as the main characteristic is hyperplasia and hypertrophy of adipose tissue cells Obesity has become more recurrent in the population due to the lifestyle change that promotes sedentary lifestyle, with dietary habits with excess calories and low fiber consumption. Affecting approximately 1.1 billion people and already considered an epidemic disease in many countries and is associated with several comorbidities, impairing the quality of patients' lives and increasing the number of associated diseases such as: type 2 cancer diabetes and cardiovascular diseases. In addition, more recent studies have shown that the pathology of these comorbidities is related to inflammatory responses of adipose tissue. Thus, based on the information exposed and the importance of the theme for collective health and well-being, this review article seeks to provide an understanding of inflammatory processes in obesity relating the involvement of adipose tissue as an endocrine organ and its biochemical mediators.
\end{abstract}

Keywords: Obesity; Inflammation; Inflammatory Markers; Diabetes mellitus

\section{Introduction}

Although today it is considered a chronic disease, for a long-time humanity has cultivated it as synonymous with opulence and charm. However, the main characteristic is hyperplasia and hypertrophy of adipose tissue cells (LEITE, ROCHA and BRANDÂO-NETO, 2009). Along with the advancement of the medical sciences it is known that it is a multifactorial disease associated with a risk heart disease, diabetes mellitus and systemic arterial hypertension (GOMES, TELO, et al., 2010).

Obesity has become more recurrent in the population due to the lifestyle change that promotes sedentary lifestyle, with dietary habits with excess calories and little fiber consumption (MIRANDA, PELUZIO and FRANCESCHINI, 2014).
Along with the accelerated demographic process, there is a constant increase in obesity worldwide (FARIA, RITTER, et al., 2019). Affecting approximately 1.1 billion people and already considered an epidemic disease in many countries (GOMES, TELO, et al., 2010) and is associated with several comorbidities, impairing the quality of patients' lives and increasing the number of associated diseases such as: type 2 diabetes cardiovascular diseases (LEITE, ROCHA and BRANDÂO-NETO, 2009).

Obesity is an important factor in which it is harmful to health and studies on the subject are necessary. In addition, more recent studies have shown that the pathology of these comorbidities is related to inflammatory responses of adipose tissue (LEITE, ROCHA and BRANDÂO-NETO, 2009).

Thus, based on the information exposed and the 
2 Aguiar, E, B.; Filho, J.C.D.F.; Silva, M.V.L.; Guimarães, D.P.O.; Ferreira, W.B.G.; Silva, P.C.; Silva, M.K.B.A.; Landim, R.A.; Silva,

L.L.F.; Silva, J.C.; Almeida, B.M.S.; Silva, M.G.S.; Santos, I.M.; Silva, H.B.G.; Lopes, A.R.O. The influence of obesity on the worsening of inflammatory processes and Diabetes..

importance of the theme for collective health and well-being, this review article seeks to provide an understanding of inflammatory processes in obesity relating the involvement of adipose tissue as an endocrine organ and its biochemical mediators.

\section{Methodology}

The production of this work occurred through the research of articles on diabetes, inflammation, obesity and inflammatory processes seeking the pathophysiology of diseases.

The research was carried out in articles available in national and international databases, where review articles and originals of journals and journals were consulted, as well as books on physiology and pathology. Soon the keywords used for research were: obesity, diabetes mellitus, inflammation and inflammatory processes. The articles and used were preferably from 2002 to 2019.

In addition, the proximity to the theme, year of publication, physiological aspects and the relationship between the pathophysiology of obesity and the promotion of inflammatory signs was taken into account. The search engines used were: PubMed, Portal Periodicals CAPES/MEC, Nature, Bireme, Lilacs, SciELO and Google Scholar.

\section{Results and Discussions}

Besides being associated with a significant number of diseases, affecting various parts of the body, obesity is a health risk if considered in isolation (LOPES, 2007). Analyzing from the cardiac perspective, it is already understood that diseases such as: hypertension, diabetes and dyslipidemias are directly linked to obesity. These diseases act as active factors in the pathological mechanisms of atheroma plaque. Thus, the appearance of cardiovascular disease the result of the osteosclerotic process. (LOPES, 2007).

In addition, recently inflammation is also being included with the factors promoting cardiac diseases (LEITE, ROCHA and BRANDÂO-NETO, 2009). Thus, obesity discovered another risk factor, since it is considered as a low-intensity inflammatory state. This is due to the fact that white adipose tissue produces a set of cytokines linked to the inflammatory pathways. (GOMES, TELO, et al., 2010).

Human adipose tissue can be classified according to the place where it is found and its function, thus we have: the white adipose tissue (BAD) that is located in the predominantly subcutaneous and visceral region, where its main function is the storage of energy in the form of triglycerides, as well as the action in the control of energy balance through the processes of lipogenesis and lipolysis; and the brown adipose tissue (TAM) found in the central nervous system has thermogenic function. (LEITE, ROCHA and BRANDÂO-NETO, 2009).

Although it was known as a passive organ with an energy reserve function, the BAD also has the function of excreting a variety of substances of local and systemic action: adipocines. With the progress of research, more than 50 adiponines have been found since 1994, where vistatine, apelin, vaspina and ometin are the most correlated with the morbidities of obesity. All of these are proportionally linked to the amount of BAD, acting similarly to insulin although they act in different sites of action (LEITE, ROCHA and BRANDÂO-NETO, 2009).

Ometine whose expression is related to increased body mass index (BMI), insulin resistance leptin and increased abdominal circumference (YANG, LEE, et al., 2006). Adding to adipocines, $\mathrm{BAD}$ is directly responsible for the production of receptors that respond to signals from the central and hormonal nervous system, with insulin, glucagon, glucagonlike peptide (GLP-1), leptin, IL-6, TNF- $\alpha$ the main ones. (KERSHAW and FLIER, 2004).

Thus, THE tA has regulatory mechanisms capable of influencing different systems such as: energy balance, immunity, inflammatory response, insulin sensitivity, angiogenesis and blood pressure (TRAYHURN and WOOD, 2004). This condition configures obesity as a low-grade chronic inflammatory disease due to increased expression of inflammatory markers and cytokines, as well as the presence of macrophages inserted in the BAD of obese individuals. Even though not all mechanisms are evident, it is already known that inflammatory processes are related to the abovementioned comorbidities of obesity diabetes mellitus, hyperlipidemia, hypotension, and metabolic syndrome. (TRAYHURN and WOOD, 2004).

The physiopathology inflammation in cases of obesity initially affects the altered expression of TNF- $\alpha$, described as a pro-inflammatory cytokine for acting in the necrosis of tumor tissues and cachexia. TNF- $\alpha$ has been shown to contribute to insulin resistance by the expression of serine kinase that prevents the expression of genes involved in the uptake and storage of free fatty acids and glucose, increasing IL-6 (TRAYHURN and WOOD, 2004).

In addition, $\mathrm{TNF}-\alpha$ to the aggravation of the arterosclerotic process. Il-6, on the other hand, is also considered pro-inflammatory, suppresses the expression of insulin receptors and receptors, contributing to insulin resistance and consequently to diabetes mellitus (LEITE, ROCHA and BRANDÂO-NETO, 2009). The elevated serum levels of these biomarkers allow to obtain information about inflammation and its processes in relation to the recruitment of macrophages and leukocytes, activation of vascular cells and oxidative stress (MIRANDA, PELUZIO and FRANCESCHINI, 2014).

When analyzing at the systemic level, the liver becomes the target of the main inflammatory markers. It has the function of supplying the metabolic essentials for stress response and for first-line defense at the site of inflammation. The liver cell is stimulated by these markers, especially TNF- $\alpha$, producing watery responses through the production of C-reactive protein (PCR) (MIRANDA, PELUZIO and FRANCESCHINI, 2014). This is a positive refeeding process, where the more TNF- $\alpha$, the more PCR in response the hepatocytes produce, stimulating the production of glycotics and other quantitative macrophage proteins, IL-1 and IL-6, bringing neutrophils and monocytes to the inflammatory focus, which in turn produce 
more TNF- $\alpha$. (MIRANDA, PELUZIO and FRANCESCHINI, the speed of fatty acid deposit in blood vessels generating the atheroma plaque, making control of inflammatory markers a promising clinical alternative (LOPES, 2007).

Diabetes is a disease related to obesity due to increased insulin resistance as described earlier. This can be proven through statistical assessments in which increased abdominal fat can increase by 10 times to calls to develop diabetes (MARIATH, GRILO, et al., 2007) and every $10 \mathrm{~kg}$ of overweight is increased $2 \mathrm{mg} / \mathrm{dl}$ in fasting glycemia (VARASCHIM, NASSIF, et al., 2012). There are several studies that make the relationship between obesity and diabetes. In one of them Helmrich et al followed for 14 years six thousand individuals, among which 202 had type 2 diabetes, where caloric expenditure and physical activity level were measured, concluding that among men the chance of an obese and sedentary is four times higher than a thin and active diabetes and develop type 2 diabetes. This information makes it clear that obesity with this comorbidity, worsening prognoses and worsening health conditions (PI-SUNYER, 2002).

\section{Conclusions}

It was found that there is a large hall of studies that report inflammatory processes in obesity, but there is still a need to clarify the biochemical mechanisms involved. Thus, more research on the subject should be conducted with a view to the best basis in clinical protocols. On the other hand, it is already well described the mechanisms with which obesity contributes to type 2 diabetes mellitus, even so epidemiological research should be done with the purpose of monitoring and promoting the health of individuals on the condition.

\section{Acknowledgements}

To my advisor Prof. MSc. Allyson Lopes, for all the support and tips offered to the beginning of the project, submission to the ethics committee, in the research conducted, in the preparation of the project presented at the congress as the conclusion of this, the teacher of CBT II for the necessary corrections, and the volunteers who participated in free consent to the research. 2014). This whole condition aggravates as already mentioned

18 May 2010. Ninety-four.

[4] KERSHAW, E. E.; FLIER, J. S. Adipose tissue as an endocrine organ. The Journal of Clinical Endocrinology \& Metabolism, Oxford, v. 89, n. 6, p. 2548-2556, 2004.

[5] MILK, L. D.; ROCHA, Yes. D. D. D. D. M.; BRANDÂONETO, J. Obesity: an inflammatory disease.

[6] Revista Ciência \& Saúde, Porto Alegre, v. 2, no. 2, p. 85-95, jul./Dec 2009.

[7] LOPES, H. F. Hypertension and inflammation: role of obesity. Revista Brasileira de Hipertensão, São Paulo, v. 14, no. Four, p. 239-244, 2007.

[8] MARIATH, A. et al. Obesity and risk factors for the development of chronic non-communicable diseases among food and nutrition unit users. Cad public health, v. 23, no. Four, p. 897-905, 2007.

[9] MIRANDA, V. P. N.; PELUZIO, M. D. D. C. G.; FRANCESCHINI, S.D. C. C. Inflammatory markers innutritional assessment: relationship with anthropometric parameters body composition and levels of physical activity. Brazilian Association of Nutrition, São Paulo, p. 61-72, Jun 2014. ISSN 2177-7527.

[10] PI-SUNYER, F. X. The obesity epidemic: pathophysiology and consequences of obesity. Obesity research, v. 10 , n. 12 , p. 97S-104S, 2002.

[11] TRAYHURN, P.; WOOD, I. S. Adipokines: inflammation and the pleiotropic role of white adipose tissue. British journal of nutrition, v. 92, n. 3, p. 347-355, 2004.

[12] VARASCHIM, M. et al. Changes in clinical and laboratory parameters in obese patients with type 2 diabetes mellitus submitted to gastrojejunal shunt in roux-sand without ring.

[13] Magazine of the Brazilian College of Surgeons, v. 39, no. 3, p. 178-182, June 2012. ISSN. https://doi.org/10.1590/S010069912012000300003.

[14] YANG, R. et al. Identification of omentin as a novel depotspecific adipokine in human adipose tissue: possible role in modulating insulin action. American Journal of PhysiologyEndocrinology and Metabolism, v. 290, n. 6, p. E1253-E1261, 2006.

\section{References}

[1] FARIA, A. P. et al. Proposal of an Inflammatory Score of Cytokines and Plasma Adipokines Associated with Resistant Hypertension, but Dependent on Obesity Parameters.

[2] Brazilian Society of Cardiology, São Paulo, v. 112, no. Four, p. 383-389, 2019.

[3] GOMES, F. et al. Obesity and Coronary Artery Disease: Role of Vascular Inflammation. Arq Bras Cardiol, São Paulo, 